\title{
Intervening Role of Metacognition to Improve Task performance in Prospective
}

\section{Teachers: An Experimental Study}

\author{
Dr. Ghazal Khalid Siddiqui*, Dr. Huma Lodhi**, Dr. Tahira Kalsoom***
}

\begin{abstract}
The teachers are trained with the aim to provide the necessary knowledge and that could help them in dealing with difficulties that they face during teaching, from the planning of a lesson to its implementation. All those skills could be developed among prospective teachers during the phase of their learning. The current study was supposeded to assess the implementation of such skills in classrooms and then measure its effect on the students' performance. For this purpose, a quasi-experiment was carried out. Consequently, two intact groups enrolled in the third semester of B.Ed. honors at a public university were considered as a sample of the study. Metacognitive Awareness Inventory (MAI) by Schraw and Dennison (1994) was adapted to test Metacognition. Parallel to this, the researcher developed rubrics and observation sheets to assess students' performance of tasks. Results of the current research reflected that metacognition development has a significant effect on the task performance of students who received the intervention. In light of these results, it is suggested that teacher training institutes should consider the development of Metacognition among their students. Teachers should incorporate different techniques that help them in inculcate metacognition development among their students.
\end{abstract}

Key Words: Metacognition, awareness, task performance, prospective teachers

This Article can be cited as:

Khalid G., Lodhi H., Kalsoom T., (2020). Intervening Role of Metacognition to Improve Task performance in Prospective Teachers: An Experimental Study, Journal of Arts and Social Sciences. VII (2), 52-59.

*Dr. Ghazal Khalid Siddiqui, Assistant Professor, University of Education, Lahore, GhazalKhalid@gmail.com.

** Dr. Huma Lodhi, Assistant Professor, University of Education Township Lahore, Huma.lodhi@gmail.com.

***Correspondence concerning this article should be addressed to Dr. Tahira Kalsoom, Assistant Professor, Lahore College for Women University, tahira.kalsoom@lcwu.edu.pk. 


\section{Introduction}

Constructive approach expresses that individuals build their knowledge by combining previous knowledge with new information and learning by interacting with their environment (Veenman, 2006). Which is more related to self-learning. This trend of self-directed learning requires that one should be able to learn and reflect using the information sought. Thus they need to be adaptable and flexible using their information in everyday routines (Hacker, 2018). Every person in today's world needs these skills to live a successful life. The mental process that implies the transformation of information, store all the relevant information after incorporating appropriate codes, and finally retrieve as per requirement is associated with cognition (Mcinerney, 2013). But contrary to this, metacognition means thinking about thinking and knowing about knowledge (Mcinerney, 2013). We can say that it is a process that refers to monitor and regulate the way we think (Mcinerney, 2013; Omrod, 2004).

Several researchers have been working upon defining the role of metacognition in the academic achievement of students at various levels of education (Dos, 2014; Hermita \& Thamrin, 2015; Sawhney \& Bansal, 2015; Young \& Fry, 2008). It is classified into three different and interactive variables of knowledge which are: personal, tasks, and strategy. According to Brown (1986), it has two main categories associated with cognition namely: metacognition knowledge (mainly concerned with self-reflection that indicates one's knowledge that he/she has regarding some particular aspect which is reflected in performing some task by utilizing that information) and regulation (system of self-regulation that an individual carries to solve his/her problems while learning). According to him, our knowledge is a combination of three types of knowledge: Declarative knowledge (all information that we already have about learning process), procedural knowledge (strategies that we opt to learn) and conditional knowledge (strategies to tackle thing in certain conditions) (as cited by Veenman et al., 2006).

Students having metacognitive skills are capable to learn in a better way as they could make a decision to solve the problems that they face after critically thinking (Kuhn \& Dean, 2004). Young, (2008) found that there was a relationship between metacognition and college students' CGPA. The teacher must be capable to have adaptive metacognition (Lin, Schwartz, \& Hatano, 2005). Especially those, who are considered to adopt teaching as a profession as they are supposed to have skills to deal with problems that they face in their classrooms. For this purpose, they are required to have updated knowledge (Veenman et al., 2006).

\section{Rationale of the Study}

Teachers who possess metacognition awareness could develop these skills in students too (Sawhney \& Bansal, 2015; Veenman et al., 2006). But contrary to this, teacher training institutes do not give much consideration towards the development of such skills. Emphasis is given to the content matter rather than the learning process (Kozikoglu, 2019). In the matter of fact, most of the teachers have only theoretical knowledge as compared to practical skills (Kozikoglu, 2019; Veenman et al., 2006).

Metacognition enables ths students to mange their learning by utilizing metaconative strategies, which leads them to achieve good grades in their exams (Jaleel \& Premachandran, 2016).

Teachers are supposd to have all information regarding content material along with the experities in using appropriate teaching methodology, as per the requirement of subject being taught and students being studied. Teachers also must be good critical thinkers and 
Critical thinking results because of metacognition (Siddiqui, 2014). If the teachers are not well aware of metacognition, how could they develop this in students?

Massive literature is available on metacognition development in students as well as its effect on students learning but very limited literature is observed regarding the development of metacognition among prospective teachers in the Pakistani context. Teachers are considered as building blocks of any nation. They are responsible to inculcate knowledge into the new generation, who are future of any nation. When they are aware of their metacognition, they could appropriately perform their assigned task. For that reason, there is a need to develop metacognitive awareness in our prospective teachers. Hence, by considering the importance of metacognition, the current study was carried out to examine its effect on prospective teachers' task performance.

Hypothesis for this study is given below:

$\mathbf{H}_{\mathbf{0}}$ : Metacognition development has not a significant effect on prospective teachers' task performance.

\section{Literature Review}

In the modern era of educational psychology, the term metacognitive has become the most attractive and fascinating term. The term Metacognition got fame after first used by John Flavell in 1976. According to him, Metacognition is comprised of regulating and monitoring aspects. But the question is what it means? The nature of this concept is dynamic and self motivated. The definition of Metacognition is the involvement of many convoluted procedures of knowing and thinking one's own thinking or knowing about knowing (Veenman, 2006). Basically, the term Metacognition is the order of higher thinking level including learner's own automated awareness about his/her ability to think, respond, understand, control along with manipulation of cognitive developmental process (Hacker, 2018). Metacognition is a combined activity of observing and controlling one's perception about cognition. It can also be defined as in process of memorization and learning how we know and respond about our cognitive processes. "Metacognition is the higher order thinking which deals with the active and dynamic control on cognition during the learning process (Mcinerney, 2013).

Although the term metacognition is considered as a part of educational psychology from last few decades, and it has been rooted with the concept of human experiences on cognition and cognitive development, but there is still a dispute about the definition and concept of metacognition (Omrod, 2004). The reason behind is that there is various associated term related to the concept, using the phenomenon of cognition considered to be same, i.e., meta comprehension, metamemory, regulation of cognition, metacognitive awareness, meta comprehension skill of self regulation, knowledge of metacognition, metacognitive regulation, metacognitive skill and so on. These terms are used off and on with slight change or synonymously (Dos, 2014; Hermita \& Thamrin, 2015; Sawhney \& Bansal, 2015; Young \& Fry, 2008). Despite the theoretical background, metacognition deals with the common understanding of cognition and there are two main components in which metacognition is divided.

Metacognitive knowledge is concerned with what the knowledge one have about the setting, situations, conditions and use of appropriate skills which will result positive skills and knowledge. These sorts of information are known as Procedural, Declarative and Conditional information (Veenman et al., 2006).

Metacognitive skills and regulation might be considered as effective activities because by using skills we engage in memorization, planning, learning, monitoring, manipulating and evaluating. Selecting specific and appropriate cognitive strategies and resources to deal with the cognitive task is referred to as planning. In order to determine progress and performance, 
the awareness about cognitive tasks must be the main focus is referred to as monitoring. Finally, by following the specific procedure and strategies the learning outcomes were achieved effectively, by ensuring the appropriate use of the regulation process, is termed as evaluation. Manipulation in metacognitive knowledge results due to manipulation in these skills (Lin, Schwartz, \& Hatano, 2005).

Literature depicts the clear image of a good student, that is to achieve the desired goal one has command on knowledge i.e., metacognitive knowledge and its related strategies. The students with good planning, monitoring, and evaluating kill have to improve learning which is categorized under good and effective metacognitive skills". In the last few decades, researchers have started their work to relate metacognition with the academic side of education(Kozikoglu, 2019). By following these studies the skills of metacognition are estimated in terms of both metacognitive knowledge and regulation. Though, these aspects are measured and discussed separately as an entity and interdisciplinary as well in literature. Lately, metacognitive skills are used to measure and explore academic achievement by adopting self report inventories (Kozikoglu, 2019; Veenman et al., 2006).

Knowledge Monitoring Ability (KMA) is a tool to evaluate the difference among students by focusing their knowledge - the domain of verbal and also estimated their performance by means of actual understanding and knowledge. A significant relationship was found among student's grades and KMA in overall GPA and in humanities, English subjects especially. Which prove that in college students' academic achievement is much relate with metacognitive regulation (Sawhney \& Bansal, 2015; Veenman et al., 2006).

The cognitive knowledge was categorized under highest test performance but the cognitive regulation was not (Schraw and Dennison, 1994). Furthermore, they suggested that by encountering MAI the cognitive knowledge can be measured by judgmental pretest. To test performance, judgmental pretests provide positive feedback.

In order to investigate the metacognitive awareness of students Sperling et al (2004) use MAI and the results showed that there is a significant correlation between metacognitive skill and metacognitive knowledge.Additionally they formulated that the Mai is not responsible for measurement of achievement. the results were surprisingly different from Schraw (1994 )results that no positive correlation was found among MAI and mathematics SAT scores.

The overall researches reveal the significant relationship among academic achievement and metacognition, which explore connection between test performance and cognitive regulation, cumulative course GPA grades and domain specific GPA (Young and Fry, 2008). To explore the different level of metacognition among students MAI is an effective tool presented by Schraw and Dennison in 1994.

\section{Methodology}

A Quasi experiment was conducted, to achieve the objective of the current study, which remained continuous throughout one semester. The B.Ed. Honors students were the population of this study. Two sections of the third semester from the one public university at Lahore were taken as (intact groups) sample. One was termed as the experimental group (consisted of 35 students) whereas the other as control (comprised of 33 students). The experimental group was used to be taught while grouping them into small groups. These students were provided the notes and required to study them while using the "Thinking Aloud" strategy. This has been recommended by (Gama, 2004) to enhance metacognitive awareness. The researcher being their teacher was used to move around the groups in order to supervise them and scaffold them as well in case of any difficulty. On the other hand, the controlled group students were taught with the traditional method (Lecture Method). 
The prospective teachers' metacognition awareness (belonging to both of the groups) was measured before the intervention as well as after the intervention too. To measure the development of metacognition awareness, Schraw \& Dennison's "Metacognitive Awareness Inventory (MAI)" was adapted by the researcher(s) that contained 35 overall items. The Instrument was validated through expert opinion and also pilot tested for its reliability measure. The value of Cronbach's alpha was .93 for this instrument.

On the other hand, the prospective teachers' task performance "Assignment" was measured with "Assessment Criteria for Report Writing" which comprised 38 items categorized under 6 factors including "Content clarity; Language; Delivery; Body Language; Engage Audience; Question Answer". Whereas "Presentation" was measured with "Oral Presentation Assessment Sheet" which consists of 8 rubrics representing "Presentation; Components of Assignment; Introduction \& Discussion; Content Organization; Format; Grammatical Errors; Conclusion; Excluded Non-Essential Information". Both of these instruments have been developed by the researcher(s). After the expert onion, they were also pilot tested for checking their reliability. The value for "Assessment Criteria for Report Writing" was .88 Cronbach's Alpha whereas .83 for "Oral Presentation Assessment Sheet".

\section{Results of Analysis}

Independent and paired sample t-tests were deployed to analyze the data, their results are presented below:

Table 1. Comparison of Prospective Teachers' Metacognitive Awareness before Treatment Belonged to Control and Experimental Group

\begin{tabular}{llllllll}
\hline & \multicolumn{9}{c}{ Control Group } & \multicolumn{3}{c}{ Experimental } \\
& \multicolumn{9}{c}{ Group } & & & \\
& $\mathrm{M}$ & $\mathrm{SD}$ & $\mathrm{M}$ & $\mathrm{SD}$ & $\mathrm{t}$ & $p$ & $d$ \\
\hline $\begin{array}{l}\text { Metacognitive } \\
\text { Awareness }\end{array}$ & 3.39 & 1.088 & 3.37 & 1.295 & -0.74 & 0.941 & 0.01 \\
\hline$* * \mathrm{p}<0.01, \mathrm{df}=66, \mathrm{~N}$ for control group $=33, \mathrm{~N}$ for experimental group $=35$ &
\end{tabular}

Results of independent sample t-test presented in the above table describe that before treatment, experimental and control groups are alike regarding overall metacognitive awareness because no significant mean difference is observed in results. In the same way, Cohen's $d$ that represents effect size was also below the range of small effect size that is 0.2 .

Table 2. Comparison of Prospective Teachers' Metacognitive Awareness after Treatment Belonged to Control and Experimental Group

\begin{tabular}{|c|c|c|c|c|c|c|c|}
\hline & \multicolumn{2}{|c|}{ Control Group } & \multicolumn{2}{|c|}{ Experimental Group } & \multirow[b]{2}{*}{$\mathrm{t}$} & \multirow[b]{2}{*}{$p$} & \multirow[b]{2}{*}{$d$} \\
\hline & $\mathrm{M}$ & SD & $\mathrm{M}$ & SD & & & \\
\hline $\begin{array}{l}\text { Metacognitive } \\
\text { Awareness }\end{array}$ & 3.47 & 0.236 & 3.89 & 0.339 & 5.96 & $0.00 * *$ & 1.44 \\
\hline
\end{tabular}

Results of independent sample t-test presented revealed that after treatment, metacognition awareness developed in students of the experimental group as compared to control group students because a significant mean difference is observed in the results. In the same way, the value of Cohen's $d$ represents the large effect size.

Table 3. Comparison of Prospective Teachers' Task Performance Before Treatment Belonged to Control and Experimental Group 


\begin{tabular}{|c|c|c|c|c|c|c|c|}
\hline & \multicolumn{2}{|c|}{ Control Group } & \multicolumn{2}{|c|}{ Experimental Group } & \multirow[b]{2}{*}{$\mathrm{t}$} & \multirow[b]{2}{*}{$p$} & \multirow[b]{2}{*}{$d$} \\
\hline & M & SD & M & SD & & & \\
\hline Presentation & 3.37 & 0.286 & 3.38 & 0.653 & 0.29 & 0.98 & 0.02 \\
\hline Assignment & 3.58 & 0.400 & 3.42 & 0.438 & -1.594 & 0.12 & 0.38 \\
\hline $\begin{array}{l}\text { Overall task } \\
\text { performance }\end{array}$ & 3.48 & 0.257 & 3.40 & 0.507 & -0.881 & 0.38 & 0.19 \\
\hline
\end{tabular}

Results of independent sample t-test presented in the above table describe that before treatment, experimental and control groups are alike regarding overall task performance as well as in its sub-factors too because no significant mean difference is observed in the results. In the same way, Cohen's $d$ that represents effect size was also below the range of small effect size that is 0.2. Opposite to this assignment has small effect size as it has $d$ value greater than 0.2 .

Table 4. Comparison of Prospective Teachers' Task Performance after Treatment Belonged to Control and Experimental Group

\begin{tabular}{|c|c|c|c|c|c|c|c|}
\hline & \multicolumn{2}{|c|}{ Control Group } & \multicolumn{2}{|c|}{ Experimental Group } & \multirow[b]{2}{*}{$\mathrm{t}$} & \multirow[b]{2}{*}{$p$} & \multirow[b]{2}{*}{$d$} \\
\hline & $\mathrm{M}$ & SD & M & SD & & & \\
\hline Presentation & 3.38 & 0.286 & 4.07 & 0.240 & 9.81 & $.000 * *$ & 2.61 \\
\hline Assignment & 3.58 & 0.400 & 4.18 & 0.379 & 7.65 & $.000 * *$ & 1.54 \\
\hline $\begin{array}{l}\text { Overall task } \\
\text { performance }\end{array}$ & 3.49 & 0.257 & 4.13 & 0.209 & 11.34 & $.000 * *$ & 2.73 \\
\hline
\end{tabular}

Results of independent sample t-test presented in the above table revealed that after treatment, the skills related to task performance developed in a better way in students of experimental group as compared to control group students because a significant mean difference is observed in the results. Similar results were observed for its sub factors. In the same way, the value of Cohen's $d$ represents the large effect size.

Table 5. Comparison of Prospective Teachers' Task Performance before and after Treatment Belonged to Experimental Group

\begin{tabular}{llllllll}
\hline & \multicolumn{2}{c}{ Before Treatment } & \multicolumn{2}{c}{ After Treatment } & & & \\
\cline { 2 - 5 } & $\mathrm{M}$ & $\mathrm{SD}$ & $\mathrm{M}$ & $\mathrm{SD}$ & $\mathrm{t}$ & $p$ & $d$ \\
\hline Presentation & 3.38 & 0.653 & 4.07 & 0.240 & -9.59 & $.000^{* *}$ & -1.62 \\
Assignment & 3.42 & 0.438 & 4.18 & 0.379 & -7.09 & $.000^{* *}$ & -1.20 \\
& & & & & & & \\
$\begin{array}{l}\text { Overall Task } \\
\text { Performance }\end{array}$ & 3.40 & 0.507 & 4.13 & 0.209 & -11.44 & $.000^{* *}$ & -1.93 \\
**p $<0.01, \mathrm{~N}=35$ & & & & & & &
\end{tabular}

Results of paired sample t-test presented in table 5 indicated that after treatment, the skills related to task performance developed in a better way in students of the experimental group in contrast to their pretest because the significant mean difference is observed in overall results as well as in its factors that were oral presentation and assignment. In the same way, the value of Cohen's $d$ represents the large effect size. 


\section{Conclusion}

The current study was conducted to identify the role of metacognition awareness in improving prospective teachers' task performance. The results of current study concluded that metacognition could be prompted in students with the help of "Thinking Aloud" strategies. On the other hand, metacognition awareness plays a significant role in the task performance of those who received the intervention as compared to those whoe were not exposed to the strategy which was supposed to improve the metacognitive awareness.

\section{Discussion}

These results are supported by the previously conducted studies by (Coutinho \& Neuman, 2008; Dos, 2014; Kuhn \& Dean, 2004; Schraw \& Moshman, 1995). According to them, the metacognition awareness can be increased while using the strategies to develop the metacognition awareness. The researcher(s) used the "Thinking Aloud" strategy to increase the prospective teachers' metacognitive awareness. It is also revealed that the students having good metacognitive awareness, achieve better results as compared to those who have poor awareness. These results have not been ooutcame from the current study alone, rather the similar type of the results also have been confirmed by different researches including (Gama, 2004; Hacker, 2018; Hermita and Thamrin, 2015; Sawhney; Bansal, 2015)

In light of these results, it is suggested that teacher training institutes should consider the development of metacognition awareness among their students. The teachers should incorporate different techniques that help them to inculcate metacognitive awareness among their students.

\section{References}

Ambrose, S. A., Bridges, M. W., DiPietro, M., Lovett, M. C., \& Norman, M. K. (2010). How learning works: Seven research-based principles for smart teaching. San Francisco: John Wiley \& Sons.

Coutinho, S. A., \& Neuman, G. (2008). A model of metacognition, achievement goal orientation, learning style and self-efficacy. Learning environments research, 11(2), $131-151$.

Dos, B. (2014). The Relationship between Mobile Phone Use, Metacognitive Awareness and Academic Achievement. European Journal of Educational Research, 3(4), 192-200.

Gama, C. (2004). Integrating metacognition instruction into interactive learning environments. (Unpublished Doctoral thesis, University of Sussex). Brighton.

Hacker, D. J. (2018). A metacognitive model of writing: An update from a developmental perspective. Educational psychologist, 53(4), 220-237.

Hermita, M., \& Thamrin, W. P. (2015). Metacognition toward academic self-efficacy among Indonesian private university scholarship students. Procedia-Social and Behavioral Sciences, 171, 1075-1080.

Jaleel, S., \& Premachandran, P. (2016). A Study on the Metacognitive Awareness of Secondary School Students. Universal Journal of Educational Research, 4(1), 165-172. 
Kozikoglu, I. (2019). Investigating Critical Thinking in Prospective Teachers: Metacognitive Skills, Problem Solving Skills and Academic Self-Efficacy. Journal of Social Studies Education Research, 10(2), 111-130.

Kuhn, D., \& Dean, J., David. (2004). Metacognition: A bridge between cognitive psychology and educational practice. Theory into practice, 43(4), 268-273.

Lin, X., Schwartz, D. L., \& Hatano, G. (2005). Toward teachers' adaptive metacognition. Educational psychologist, 40(4), 245-255.

Mcinerney, D. M. (2013). Educational psychology: Constructing learning. Australia: Pearson Higher Education.

Omrod. (2004). Educational Psychology. USA: Pearson Publication.

Sawhney, N., \& Bansal, S. (2015). Metacognitive awareness of undergraduate students in relation to their academic achievement. The International Journal of Indian Psychology, 3(1), 107-114.

Schraw, G. and Dennison, R. S. (1994). Assessing metacognitive awareness. Contemporary Educational Psychology, 19, 460-475.

Schraw, G., \& Moshman, D. (1995). Metacognitive theories. Educational Psychology Review, 7(4), 351-371.

Sperling, R. A., Howard, B. C., Staley, R. and DuBois, N. (2004). Educational Research and Evaluation, 10(2), 117-139.

Siddiqui, G. K. (2014). Development of metacognitive skills in prospective teachers and its relation to their task perfromance. (Doctoral Thesis), University of the Punjab, Lahore, Pakistan.

Veenman, M. V., Van Hout-Wolters, B. H., \& Afflerbach, P. (2006). Metacognition and learning: Conceptual and methodological considerations. Metacognition and learning, 1(1), 3-14.

Young, A., \& Fry, J. D. (2008). Metacognitive awareness and academic achievement in college students. Journal of the Scholarship of Teaching and Learning, 8(2), 1-10. 